\title{
PROGRADAÇÃO DELTAICA TIBAGI NO DEVONIANO MÉDIO DA BACIA DO PARANÁ
}

\author{
MÁRIO L. ASSINE*, JOSÉ ALEXANDRE J. PERINOTTO*, VICENTE J. FULFARO*, SETEMBRINO PETRI**
}

\begin{abstract}
TIBAGI DELTAIC PROGRADATION IN THE MIDDLE DEVONIAN OF THE PARANÁ BASIN The Ponta Grossa Formation (Devonian) is made up mainly of fossiliferous marine shales, comprising two sub-basins: Apucarana (south) and Alto Garças (north). The members Jaguariaíva (base), Tibagi and São Domingos (top), previously recognized in the Apucarana sub-basin, have been extended to the Alto Garcas sub-basin. The Tibagi Member is characterized by coarsening and thickening upward sandstones, recording a progradational event in a highstand sea levei tract placed between two maximum-flooding surfaces in the Emsian (Jaguariaiva Member) and in the Givetian (São Domingos Member). Herein, the Tibagi Member hás been traced from the Apucarana sub-basin to the Alto Garças sub-basin, based on geological cross-sections using well logs in the central part of the basin and outcrop data in Goiás State. In the Alto Garças sub-basin the Ponta Grossa Formation rests unconformably on the Early Devonian Furnas Formation with a transgressive lag deposit enhancing an erosive phase. In vertical stratigraphic profiles the Tibagi progradational pilled up parassequences are arranged from marine storm wave-dominated shelf environment to deltaic distributary channels. The segmentation of Devonian strata into two sub-basins, separated by syndepositional highs, along with unconformity between Furnas and Ponta Grossa formations at the eastern part of the Alto Garças sub-basin, and the progradation of clastic wedges from east to west are evidence of synsedimentary tectonics in the Paraná basin during the Middle Devonian.
\end{abstract}

Keywords: Devonian, Tibagi Member, Paraná basin, deltaic progradation

RESUMO O Membro Tibagi é a unidade intermediária da Formação Ponta Grossa e caracteriza-se pela existência de corpos arenosos intercalados em folhelhos marinhos. Os arenitos estão organizados em sequências de fácies que apresentam padrão de granocrescência ascendente e de espessamento dos corpos arenosos para o topo, exibindo frequentemente estratificação cruzada hummocky. Seções regionais permitiram verificar a continuidade da unidade em subsuperfície em praticamente toda a bacia. Na faixa aflorante no Estado de Goiás, o contato entre as formações Furnas e Ponta Grossa é discordante e marcado pela presença de lags transgressivos. Em perfis estratigráficos verticais pode-se verificar empilhamento progradacional pela superposição de várias parasseqüências, de plataforma marinha dominada por ondas de tempestade na base a canais deltaicos distributários no topo, estes caracterizados pela presença de arenitos conglomeráticos. O contexto geral da Formação Ponta Grossa é transgressivo e o Membro Tibagi constituiu progradação num trato de sistemas de mar alto. A existência de discordância entre as formações Furnas e Ponta Grossa na faixa aflorante no Estado de Goiás, a ativação de altos sindeposicionais e consequente origem de lacunas no registro sedimentar, a movimentação nas áreas-fonte a leste e progradacão de sistemas deltaicos, e a segmentacão do sítio deposicional nas sub-bacias de Apucarana e Alto Garças, são evidências de tectonismo sinsedimentar na Bacia do Paraná durante o Devoniano Médio.

Palavras-chave: Devoniano, Membro Tibagi, Bacia do Paraná, progradação deltaica

INTRODUÇÃO A Formação Ponta Grossa é uma unidade devoniana predominantemente pelítica, cujo paleoambiente marinho plataformal é atestado por ampla variedade de macro (trilobitas, braquiópodos, tentaculites etc) e microfósseis (acritarcas, quitinozoários etc). Lange (1967) e Daemon et al. (1967), analisando respectivamente quitinozoários e esporomorfos, subdividiram a Formação Ponta Grossa em quatro intervalos bioestratigráficos informais, mas de amplo uso desde então. Os intervalos, identificados por letras, correspondem aproximadamente aos andares Emsiano (D2), Eifeliano (D3), Givetiano (D4) e Frasniano (D5).

A seção mais representativa da unidade é a do poço 2-AP1-PR (Apucarana), onde foram perfurados $654 \mathrm{~m}$, mas sua espessura é bastante variável em área delineando duas subbacias ou baixos estruturais, que Ramos (1970) denominou Apucarana e Alto Garças (Fig. 1).

No Estado do Paraná, onde se sobrepõe concordantemente à Formação Furnas, a Formação Ponta Grossa foi subdividida em três membros (Jaguariaíva, Tibagi e São Domingos) por Lange e Petri (1967), que propuseram sua aplicação em toda a bacia.

O Membro Jaguariaíva é a unidade basal da Formação Ponta Grossa. Constitui um pacote homogéneo de folhelhos sílticos de coloração cinza média/escura, frequentemente bioturbados. De idade praguiana-emsiana (Lange 1967, Loboziak et al. 1995), os folhelhos são muito fossilíferos e portadores de formas malvinocáfricas, sobretudo braquiópodes e trilobitas. Sua espessura varia entre 50 e 100 m nas faixas de afloramento, valores que se repetem na maioria dos poços. $\mathrm{Na}$ metade superior ocorrem folhelhos pretos com teores relativamente altos de matéria orgânica, constituindo um intervalo potencialmente gerador de hidrocarbonetos na bacia. A seção-tipo, com cerca de $100 m$ de espessura, foi levantada por Petri (1948) nos arredores da cidade de Jaguariaíva.

O Membro Tibagi sobrepõe concordantemente o Membro Jaguariaíva. Posicionado no Eifeliano (Lange 1967), é caracterizado pela presença de arenitos finos a muito finos, lenticulares e fossíliferos (tipicamente Australospirifer iheringi), intercalados em folhelhos sílticos. Seções de até $150 \mathrm{~m}$ foram constatadas em vários poços, sendo comum a recorrência de corpos arenosos. A seção clássica é a das cabeceiras do arroio São Domingos (Tibagi-PR), caracterizada pela presença de corpos de arenitos com 20m de espessura (Oliveira 1927).

O Membro São Domingos é a unidade de topo, constituindo uma seção de folhelhos cinza de idade givetiana-frasniana (Lange 1967, Daemon et al. 1967). A fauna é semelhante à do Membro Jaguariaíva, mas representada por menor número de espécies, faltando formas tipicamente malvinocáfricas (Melo 1988). Na área-tipo, a oeste de Tibagi-PR, Maack (1950-51) mediu uma seção com $90 \mathrm{~m}$ de espessura. Expressivas seções ocorrem em subsuperficie, atingindo valores da ordem de $350 \mathrm{~m}$ no poço 2-AP-1-PR (Apucarana), onde um intervalo regressivo frasniano (Daemon et al. 1967) foi preservado da erosão carbonífera que gerou a discordância no topo da unidade. De acordo com dados palinológicos mais recentes, na porção norte da bacia ficaram preservados da

* Unesp/ IGCE/Departamento de Geologia Sedimentar - Av. 24-A./1515, CP 178, CEP 13506-900, Rio Claro-SP, Brasil -e-mail: assine@caviar.igce.unesp.br

** USP / IG / Departamento de Paleontologia e Estratigrafia - Rua do Lago / 562, Cidade Universitária, CEP 05508-900, São Paulo-SP, Brasil 


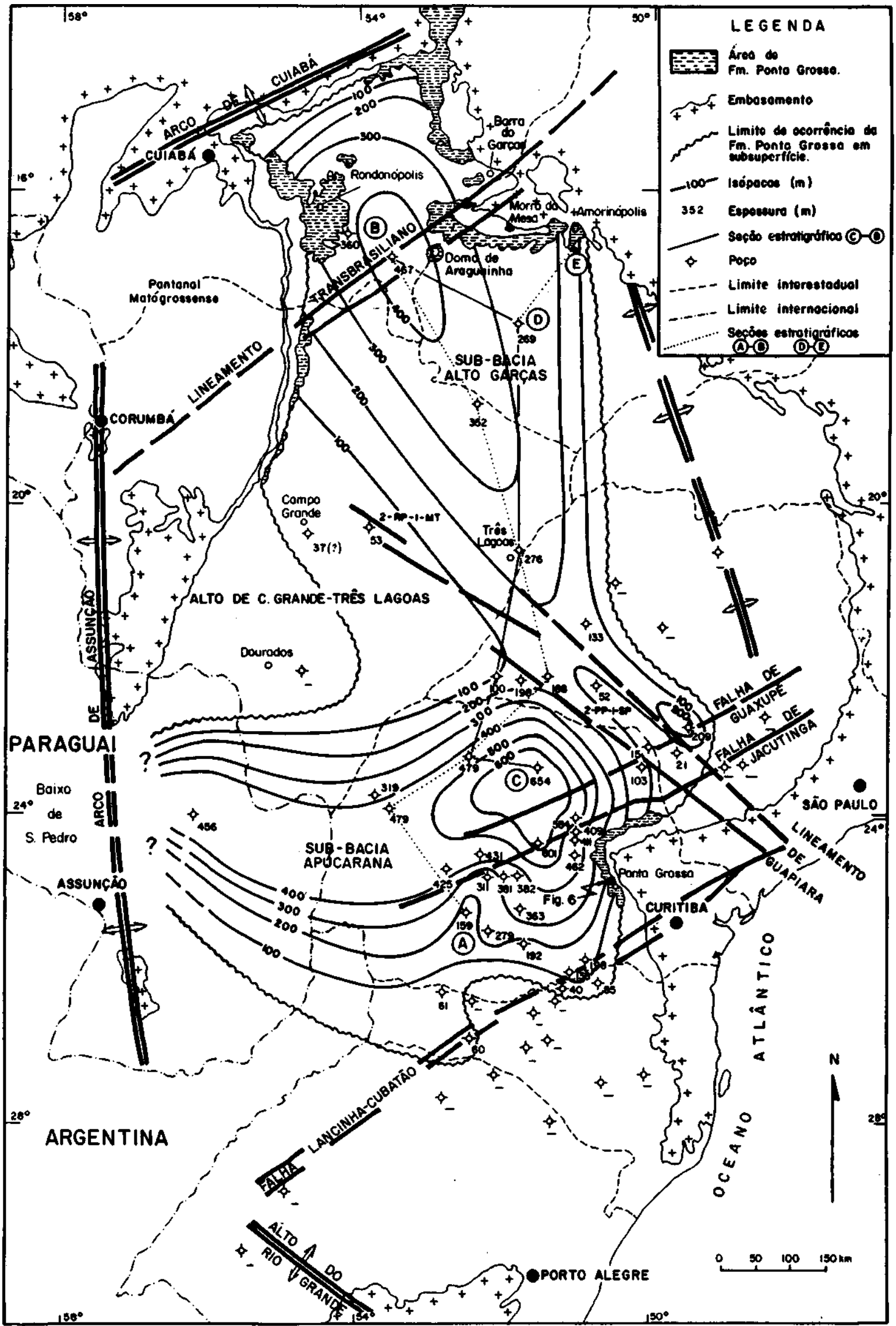

Figura l- Mapa de isópacas da Formação Ponta Grossa (Assine 1996). É nítida a compartimentação tectônica em duas sub-bacias, Alto Garças (norte) e Apucarana (sul), separadas por um alto de direção aproximada leste-oeste

Figure 1 - Isopach map of the Ponta Grossa Formation (Assine 1996) displaying an east-west high and two sub-basins: Alto Garças (north) and Apucarana (south) 
erosão estratos de idade famenniana (Loboziak et al. 1995), ficando em aberto a possibilidade da sedimentação ter-se prolongado até o Carbonífero.

A subdivisão tripartite de Lange e Petri (1967) não foi adotada por Andrade e Camarço (1980) e Melo (1988), que consideraram haver diferenças marcantes no empilhamento estratigráfico da Formação Ponta Grossa nas porções nordeste e norte da bacia. Esta concepção não foi compartilhada por Assine et al. (1994) que, utilizando os perfis dos poços perfurados na bacia, mostraram a continuidade física dos membros Jaguariaíva, Tibagi e São Domingos em subsuperfície.

Trilhando esta última linha de raciocínio e tendo por base estudo sobre as sequências pré-carboníferas da Bacia do Paraná apresentado à Universidade de São Paulo como tese de doutorado (Assine 1996), este trabalho tem como objetivo principal a análise estratigráfica regional do Membro Tibagi.

CORRELAÇÃO ESTRATIGRÁFICA Na seção estratigráfica da figura 2, observa-se que a subdivisão de Lange e Petri (1967) tem expressão regional, sendo factível o reconhecimento dos membros Jaguariaíva, Tibagi e São Domingos nas sub-bacias de Apucarana e de Alto Garças.

Duas superfícies de inundação máxima na Formação Ponta Grossa estão indicadas na seção da figura 2, correspondendo a dois picos de transgressão na sequência devoniana da Bacia do Paraná. Os dois picos são facilmente reconhecidos nos perfis de raios-gama pois coincidem com valores altos de radioatividade. Entre as duas superfícies de inundação máxima, uma no Membro Jaguariaíva (Emsiano) e outra no Membro São Domingos (Givetiano), ocorrem os arenitos do
Membro Tibagi (Eifeliano) que materializam evento regressivo progradante (Fig. 3).

A subdivisão tripartite só não é observada quando a seção está incompleta. Isto pode ter resultado de erosão no topo durante a génese da discordância com unidades carboníferas, caso em que não ficaram preservados estratos meso e neodevonianos (observar preservação irregular da parte superior da Formação Ponta Grossa na figura 2). A não ocorrência das três unidades pode ter resultado também de erosão e/ou não-deposição dos membros inferiores em situação de borda de bacia ou em paleoaltos internos sindeposicionais. Esta relação é mostrada na seção estratigráfica da figura 4 , onde se verifica falta de seção nos poços 2-TL-1-MS (Três Lagoas) e 2-JA-1GO (Jataí).

A correlação apresentada na figura 4 é corroborada pelos dados bioestratigráficos de Lange (1967) e Daemon et al. (1967), que evidenciam ausência dos intervalos bioestratigráficos D2 e D3 no registro do poço 2-TL-1 -MS. Os mesmos autores constataram falta de seção correspondente aos intervalos D2 e D3 em outros poços da bacia, como por exemplo no 2-RP-l-MS (Ribas do Rio Pardo) e no 2-PP-l-SP (Paraguaçu Paulista), cujas localizações podem ser encontradas na figura 1.

Quando os membros inferiores (Jaguariaíva e/ou Tibabi) estão parcialmente preservados ou não ocorrem, contatos discordantes com a Formação Furnas são observados. No Alto de Campo Grande - Três Lagoas, que divide a sub-bacia de Alto Garças da de Apucarana, folhelhos transgressivos givetianos do Membro São Domingos jazem diretamente sobre a Formação Furnas (Fig. 5).

(A)

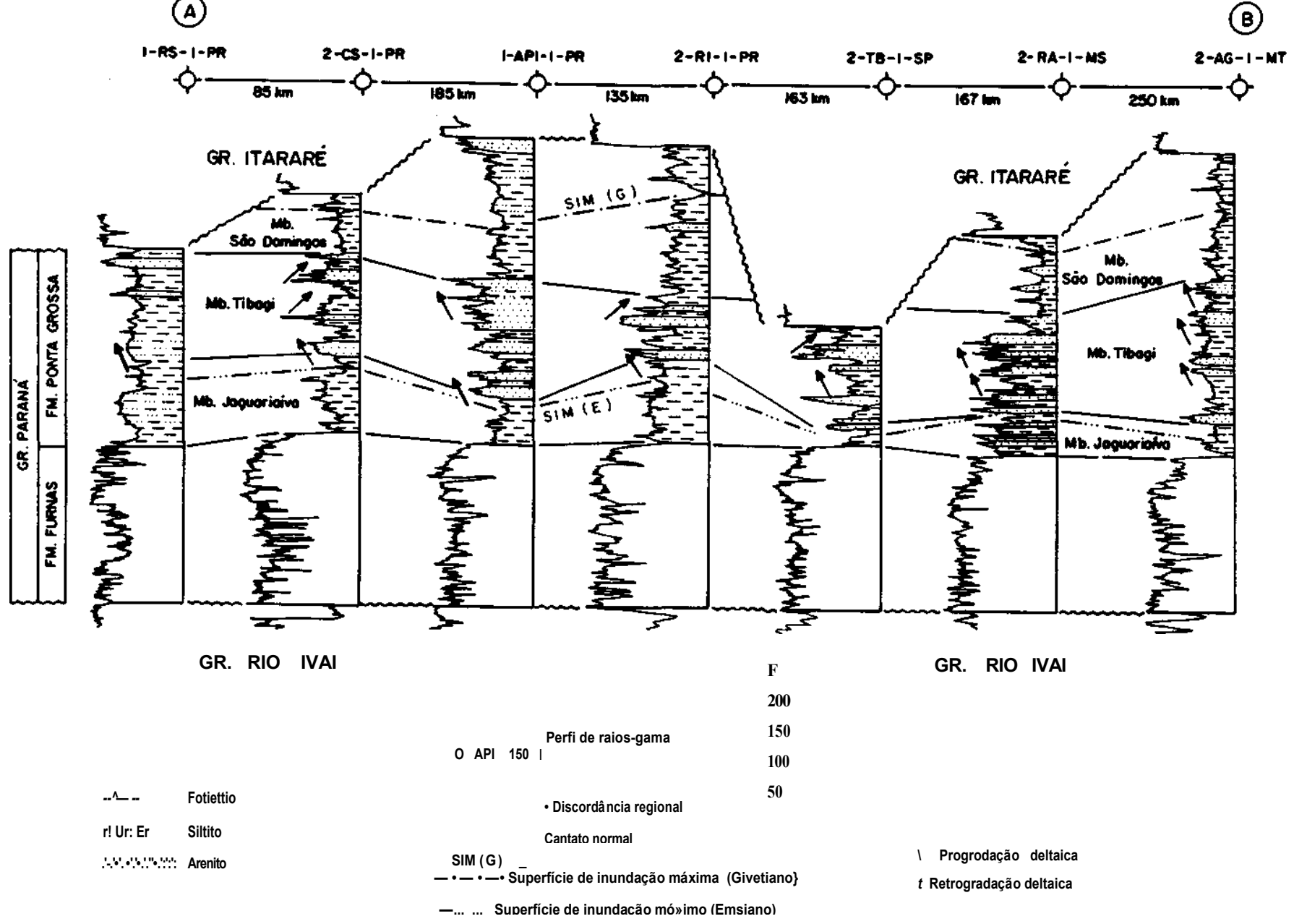

Figura 2 - Seção estratigráfica mostrando a viabilidade da subdivisão tripartite da Formação Ponta Grossa (localização na figural).

Figure 2 - Stratigraphic cross-section showing the feasibility of the tripartite subdivision of the Ponta Grossa Formation (see figure 1 for location) 


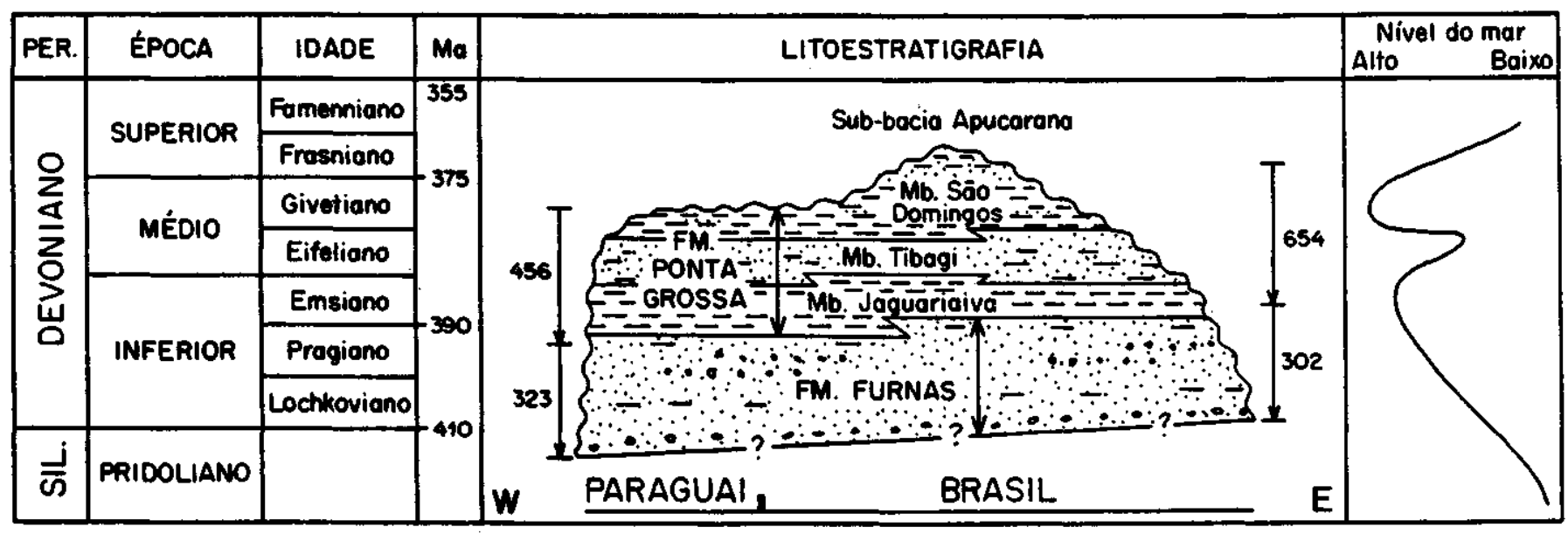

Figura 3 - Carta cronoestratigráfica leste-oeste (espessura máxima em metros indicada na vertical) Figure 3 - East-west chronostratigraphic chart (maxiraum thickness in meters indicated)

(C)
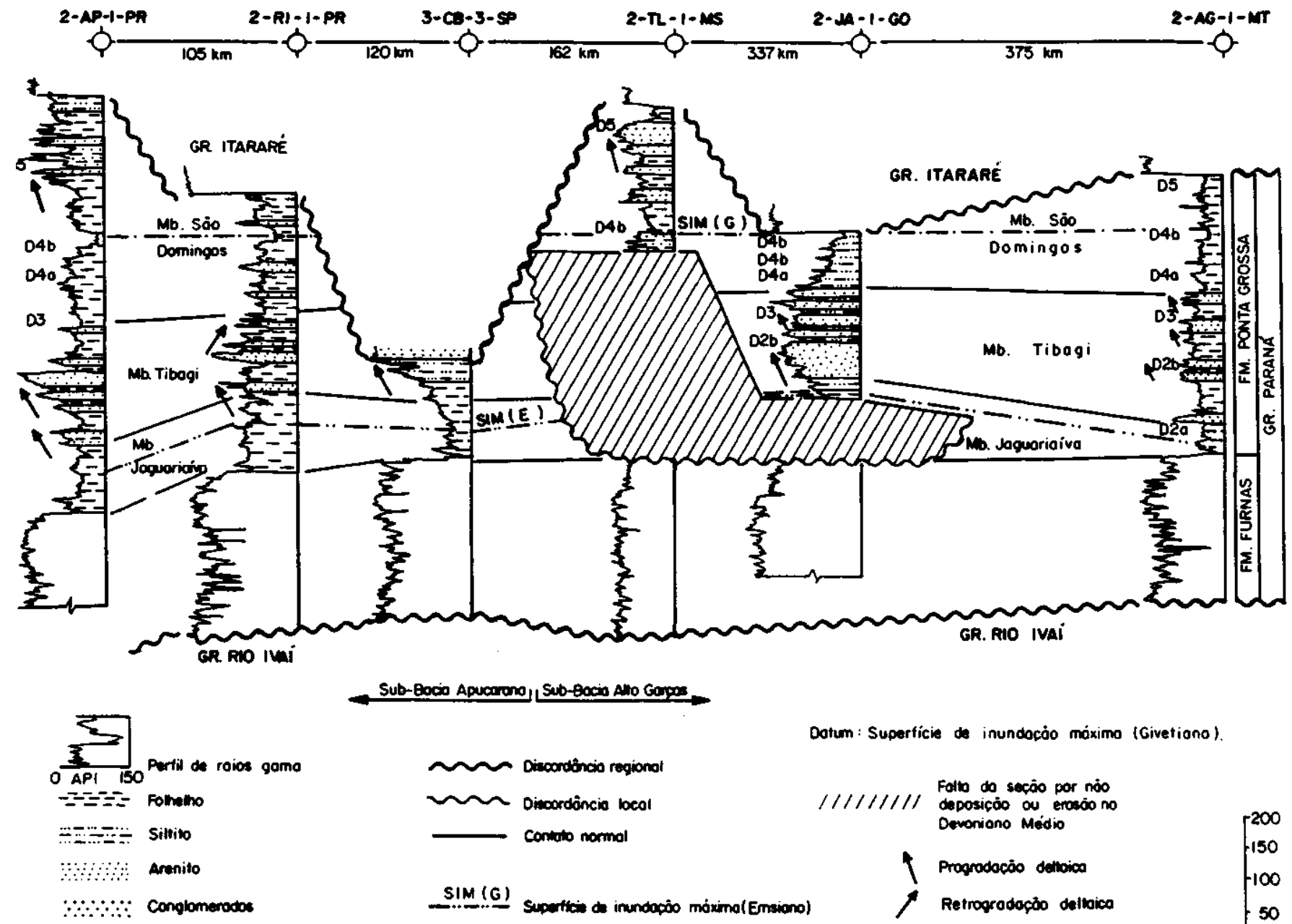

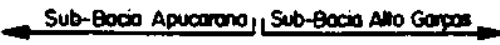

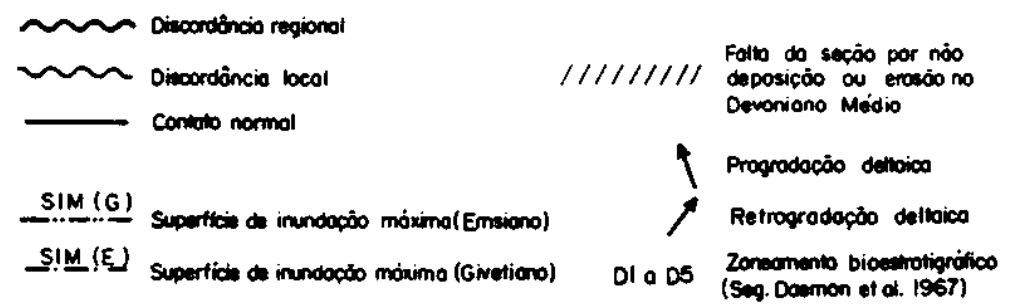

Figura 4 - Seção estratigráfica mostrando falta de seção entre as formações Furnas e Ponta Grossa em altos sindeposicionais (localização na figura 1)

Figure 4 - Stratigraphic cross-section showing stratigraphic gaps between Furnas and Ponta Grossa formations in syndepositional highs (see figure l for location). 


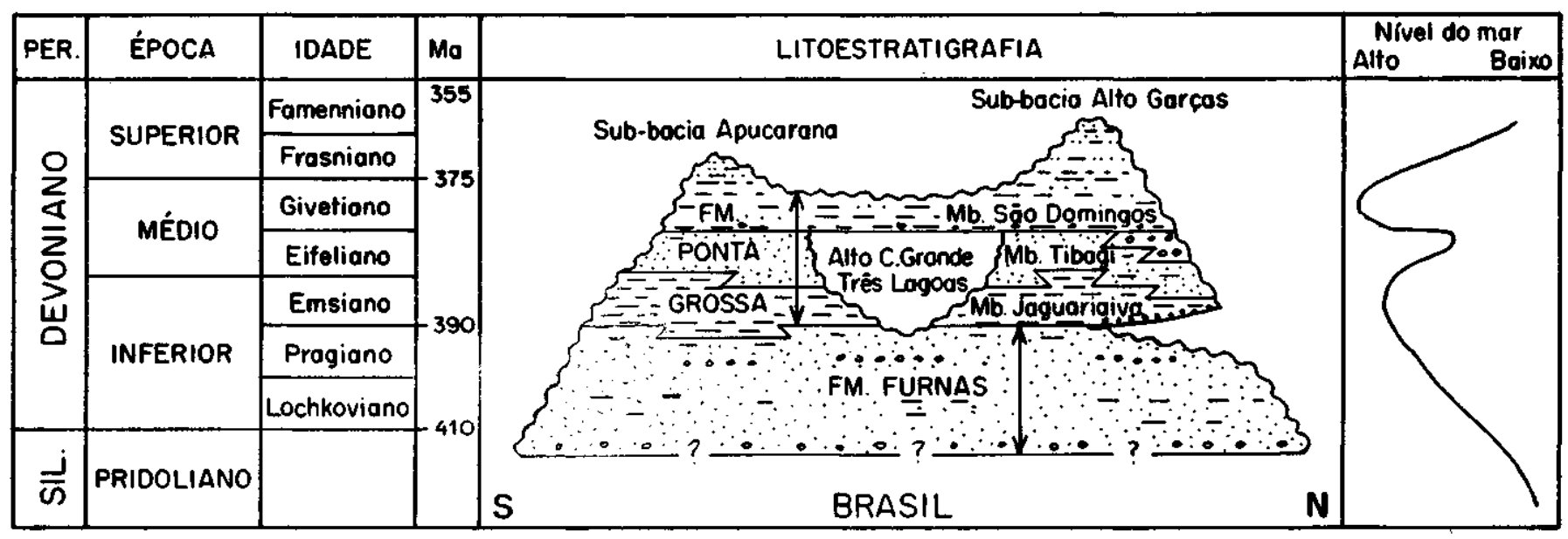

Figura 5 - Carta cronoestratigráfica norte-sul mostrando contatos discordantes entre as formações Furnas e Ponta Grossa em altos sindeposicionais, fato já destacado em Assine (1995)

Figure 5 - North-south chronostratigraphic chart showing unconformity between Furnas and Ponta Grossa formations in syndepositional highs, as discussed in Assine (1995)

\begin{abstract}
ARENITOS DO MEMBRO TI B AG I NO ESTADO DO
PARANÁ Existem poucas referências sobre afloramentos dos arenitos do Membro Tibagi na literatura geológica. Além da ocorrência na seção-tipo em Tibagi, Maack (1950-51) descreveu duas outras ocorrências de corpos arenosos com até $35 \mathrm{~m}$ de espessura a norte daquela cidade. Petri (1948) reconheceu também os arenitos do Membro Tibagi mais para sul (região de Lambedor), onde identificou sete camadas de arenitos densamente fossilíferas (grandes espécimes de Australospirifer iheringi).
\end{abstract}

Na região de Ponta Grossa, Lange e Petri (1967) descreveram uma seção de arenitos finos em cujo topo se apresenta um delgado nível de arenitos argilosos contendo seixos discóides dispersos (km 14,3 da antiga Estrada de Ferro Central do Paraná). Sobre o nível de seixos foram caracterizadas mais três camadas de arenitos com espessuras entre 0,5 e 1,5 $\mathrm{m}$, com padrão textural de granocrescênciaem direção ao topo (Fig. 6). Tanto os arenitos quanto os folhelhos e siltitos intercalados apresentam fragmentos vegetais de Spongiophyton. Por estarem sotopostos a folhelhos datados como givetianos (Lange 1967, Daemon et al. 1967), Lange e Petri (1967) concluíram que o afloramento representa o contato entre os membros Tibagi e São Domingos.

Os arenitos do Membro Tibagi constituem corpos com frequente padrão textural de granocrescência para o topo. São comumente finos a muito finos, sílticos, micáceos, apresentando estratificação plano-paralela, ondulada ou cruzada hummocky, quando não obliterada por bioturbação. A interestratificação com folhelhos fossilíferos marinhos, as estruturas sedimentares presentes e os fósseis de braquiópodos, em especial do género Australospirifer, indicam deposição em sistemas marinhos plataformais sob a ação de ondas.

Como nas modernas plataformas dominadas por ondas, a sedimentação foi episódica, alcançando taxas máximas de deposição durante tempestades, com a edificação de barras arenosas retrabalhadas por ondas, e mínimas durante prolongados períodos de tempo bom, quando pelitos se formaram pela decantação de partículas finas. Esta é a explicação atual para o que antigamente parecia paradoxal: a íntima associação entre arguas marinhas plataformais e depósitos elásticos grossos, estes interpretados como depósitos formados durante eventos episódicos de alta energia (tempestades).

\section{ARENITOS DO MEMBRO TIBAGI NO ESTADO DE} GOIÁS Na extremidade leste da faixa aflorante no Estado de Goiás, a base da Formação Ponta Grossa é marcada por horizonte de cascalhes (diâmetro dos clastos: máximo constatado de $21 \mathrm{~cm}$ ), que pode variar desde uma superfície com clastos dispersos e isolados até uma camada de conglomerado com alguns decímetros de espessura (Fig. 7), e por isso referida como conglomerado basal por Andrade e Camarço (1980). Trata-se de um extenso depósito residual transgressivo (transgressive lag) formado como consequência de rápida transgressão erosiva, com retrabalhamento e joeiramento (winnowing) do substrato (Formação Furnas). O contato entre as formações Furnas e Ponta Grossa é, neste caso, discordante.

Os depósitos residuais são recobertos por delgado nível de siltitos marinhos intensamente bioturbados, cujo conteúdo palinológico permitiu o posicionamento da base da Formação Ponta Grossa no Emsiano superior (R. F. Daemon, informação escrita 1995). Esta idade é compatível com o topo do Membro Jaguariaíva no Estado do Paraná.

Espessa seção psamítica sobrepõe estes siltitos transgressivos basais. $\mathrm{O}$ padrão de granocrescência ascendente dos corpos arenosos e do conjunto como um todo é exatamente o mesmo observado no Membro Tibagi no Estado do Paraná. Além disso, os arenitos são fossilíferos com a presença marcante do braquiópode Australospirifer iheringi (Andrade e Camarço 1980).

O contato com a Formação Furnas é geomorfologicamente bastante nítido, definido por uma quebra topográfica entre arenitos brancos, grossos e mal selecionados da Formação Furnas e arenitos branco-avermelhados, finos a muito finos, da Formação Ponta Grossa. Este constraste é particularmente evidente no Morro da Mesa (Fig. 8), situado nas proximidades da localidade de Vila Maria.

Excelente seção do Membro Tibagi está exposta a sul de Amorinópolis, onde se verifica a predominância, na parte inferior, de arenitos finos a muito finos, bem selecionados, micáceos, com estratificação cruzada hummocky quando não totalmente bioturbados (membro inferior de Andrade e Camarço 1980). Na parte superior se apresentam intercalações de arenitos com granulometria média a muito grossa, por vezes conglomerática (membro médio de Andrade e Camarço 


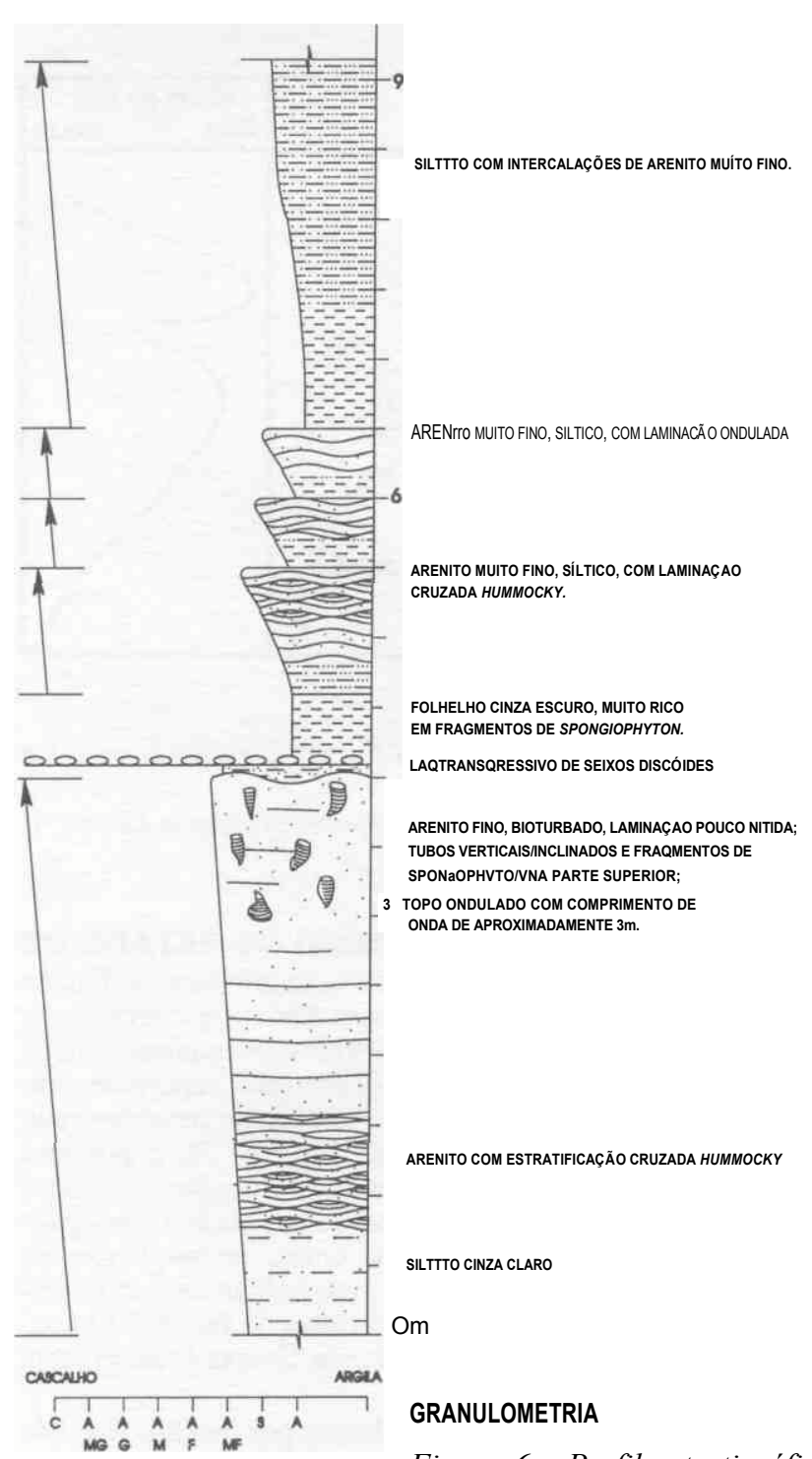

Figura 6 - Perfil estratigráfico vertical no bairro Santa Luzia, em Ponta Grossa-PR (antigo km14,3 da Estrada de Ferro Central do Paraná, referido em Lange e Petri 1967). As setas indicam padrões de granocrescência ascendente na Formação Ponta Grossa. Localização na figura $l$ Figure 6 - Vertical stratigraphic profile at Santa Luziadistrict, PontaGrossa-PR (km 14,3 Ferro Central do Paraná railway, refered by Lange e Petri 1967). The aiTows indicate coarsening upward pattern in the Ponta Grossa Formation. Location on figure 1

1980). Na figura 9 é apresentada a correlação do perfil do poço 2-JA-1-GO (Jataí) com o perfil estratigráfico levantado no local, verificando-se espessamento do Membro Jaguariaíva para sul em direção àquele poço.

O Membro Tibagi adquire suas máximas possança e razão elástica em Goiás, atingindo cerca de $200 \mathrm{~m}$ de espessura no Município de Caiapônia. A existência de níveis conglomeráticos no topo, que espessam para leste em detrimento dos arenitos da base, reflete proximidade da borda original da bacia.

No Estado de Goiás o empilhamento reflete condições de borda, caracterizando-se pela presença de deltas retrabalhados por ondas com sentido de progradação de NE para SW, polaridade esta deduzida a partir da distribuição das fácies

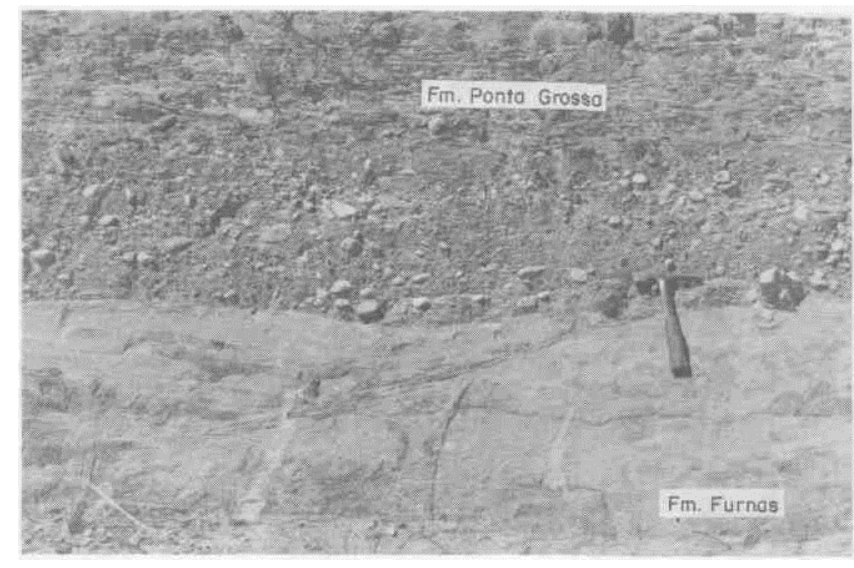

Figura 7 - Depósito residual transgressivo no contato entre as formações Furnas e Ponta Grossa no Estado de Goiás. Figure 7 - Transgressive lag between Furnas and Ponta Grossa formations in Goiás State

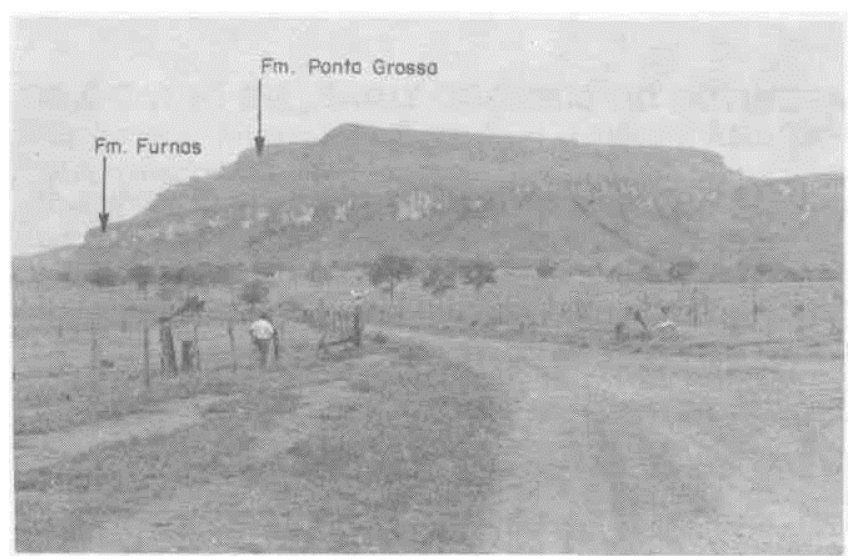

Figura 8 - A natureza psamítica da parte inferior da Formação Ponta Grossa no sul de Goiás é responsável por relevos escarpados como o do morro da Mesa (localização na figura 1).

Figure 8 - The psamitic nature of the lower Ponta Grossa Formation in Goiás State results in scarpments such as the morro da Mesa (location on figure 1)

(Andrade e Camarço 1980) e do padrão de paleocorrentes nas fácies de planície deltaica (parte superior do perfil estratigráfico levantado a sul de Amorinópolis e apresentado na figura 9).

Uma espessa seção pelítica, de idades givetiana a famenniana, constitui a parte superior da Formação Ponta Grossa no flanco nordeste da bacia. Referida como membro superior por Andrade e Camarço (1980), representa a exposição em superfície do Membro São Domingos, presente nos poços 2-JA-1GO, 2-RA-1-MS e 2-AG-1-MT.

\section{PROGRADAÇÃO NUM TRATO DE SISTEMAS DE}

MAR ALTO Os sedimentos marinhos emsianos que deram origem ao Membro Jaguariaíva foram depositados em condições de baixa energia, com taxas de sedimentação muito baixas e intensa colonização bentônica, do que resultaram estratos intensamente bioturbados e muito fossilíferos, constituindo os horizontes paleontologicamente mais ricos da Formação Ponta Grossa. Fósseis na posição de vida foram obser- 


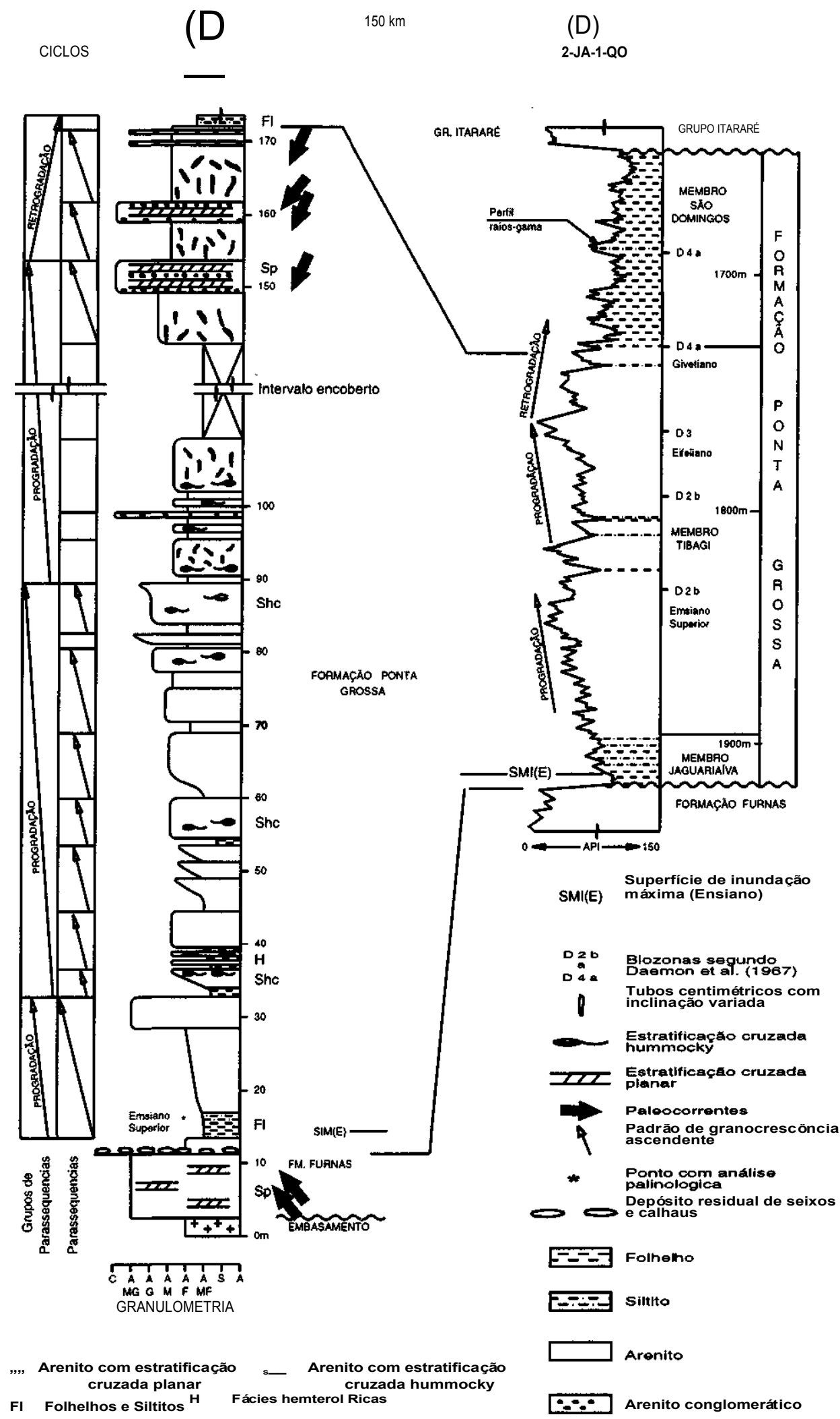

Figura 9 - Perfil estratigráfico vertical levantado a sul de Amorinópolis (GO) e sua correlação com o perfil do poço Jataí $n^{\circ} 1$ (seção estratigráfica D-E na figura 1). Os arenitos do Membro Tibagi estão organizados em várias parasseqüências com granocrescência ascendente, que no seu conjunto exibem padrão progradacional. No perfil de Amorinópolis verifica-se redução de espessura do Membro Jaguariaíva e a existência de depósitos residuais transgressivos no contato entre as formações Fumas e Ponta Grossa.

Figure 9 - Vertical stratigraphic profile measured in outcrop south of Amorinópolis (Goiás) and its correlation with lithologic and gamma-ray log of the Jataí well (D-E stratigraphic cross-section on figure 1). The Tibagi sandstones are organized in several coarsening upward parassequences exhibiting a progradational piling up pattem. The thickness of the Jaguariaíva Member decreases northward to Amorinópolis and the contact between Furnas and Ponta Grossa formations is marked by transgressive pebble lags. 
vados, tendo sido relatados anteriormente por Lange e Petri (1967) e Diniz (1985).

Nos folhelhos do Membro Jaguariaíva registra-se o clímax de uma tendência ascendente de aumento da radioatividade e/ou argilosidade, que se inicia na parte superior da Formação Furnas. Caracteriza-se como um pico de radioatividade a partir do qual os valores voltam novamente a decrescer, por isso interpretado como a superfície de inundação máxima no Eodevoniano. Durante o período de inundação máxima o aporte terrígeno foi mínimo, materializando uma zona de condensação na qual são comuns folhelhos pretos ricos em matéria orgânica. Seções marinhas condensadas têm espessura geralmente de poucos metros e tipicamente se apresentam como picos de radioatividade nos perfis de raios-gama. Os pelitos existentes na base da seção levantada a sul de Amorinópolis (Fig. 9), que jazem diretamente sobre os lags transgressivos existentes no contato entre as formações Furnas e Ponta Grossa, são interpretados como o registro continente adentro deste pico de máxima inundação no Emsiano.

O empilhamento descrito é plenamente reconhecido na sub-bacia de Apucarana, tanto na faixa de afloramentos no Estado do Paraná como em quase todos os poços, caracterizando um trato de sistemas transgressivo. Na sub-bacia de Alto-Garças o mesmo empilhamento pode ser observado no poço 2-AG-1-MT.

Da superfície de inundação máxima até o topo do Membro Tibagi tem-se um típico trato de sistemas de mar alto (highstand systems tracf). Arenitos com padrões de granocrescência ascendente caracterizam o Membro Tibagi, sendo visíveis nos perfis de raios-gama de praticamente todos os poços em que a unidade ocorre (Figs. 2 e 4). Não só as sequências de fácies apresentam padrão textural de granocrescência ascendente, mas também a sequência como um todo, o que reflete aumento da porcentagem da fração areia em direção ao topo. Este padrão é característico de progradações deltaicas, tendo sido anteriormente ressaltado por Diniz (1985) e Popp e Barcellos-Popp(1986).

Na seção da figura 9, o empilhamento evidencia a presença de deltas retrabalhados por ondas de tempestade, num padrão de granocrescência ascendente que culmina com o avanço de fácies de planície deltaica. Várias sequências de fácies com granocrescência ascendente podem ser observadas, desde arenitos de plataforma dominada por tempestades (shelfsand ridges) na base até arenitos conglomeráticos de canais deltaicos distributários na parte superior.

As espessuras e o caráter litológico do Membro Tibagi indicam situação proximal no Estado de Goiás, ou seja, a área era próxima da borda original da bacia à época. Além disso, a Formação Ponta Grossa avançou para além dos limites orientais da Formação Furnas assentando-se diretamente sobre o embasamento pré-cambriano/ eopaleozóico a leste da cidade de Amorinópolis, caracterizando recobrimento em onlap de oeste para leste.

Na faixa de afloramentos no Estado do Paraná, o Membro Tibagi compreende fácies de plataforma externa dominada por tempestades, onde barras arenosas de costa-afora ocorrem intercaladas em folhelhos plataformais. As fácies foram geradas em posições distais de tratos de mar alto, estando hoje aflorantes e parcialmente erodidas em consequência do soerguimento do Arco de Ponta Grossa no Mesozóico. Neste evento, que promoveu a exposição de rochas das porções mais centrais da sub-bacia de Apucarana, foram removidas por erosão as fácies deltaicas contíguas a leste.

Em tratos de sistemas de mar alto pode ocorrer regressão por progradação com nível do mar estacionário, desde que o afluxo sedimentar seja mais signifcativo que a capacidade de erosão dos agentes marinhos costeiros. Os depósitos deltaicos assim gerados são preservados no registro sedimentar quando sobrepostos por tratos transgressivos, sem a interveniência de quedas significativas do nível de base. Não havendo erosão significativa, os depósitos de planície deltaica do topo do Membro Tibagi em Goiás ficaram preservados, mesmo num contexto de borda de bacia.

Do topo do Membro Tibagi até a superfície de inundação máxima no Givetiano, tem-se outro trato de sistemas transgressivo (parte inferior do Membro São Domingos). Os sedimentos marinhos pelíticos do trato transgressivo jazem diretamente sobre depósitos deltaicos e/ou marinhos plataformais do topo do Membro Tibagi, caracterizando limite de duas sequências deposicionais. A base do Membro São Domingos é transgressiva, por vezes com o desenvolvimento de delgados depósitos residuais (lags transgressivos), como os descritos por Lange e Petri (1967) em Ponta Grossa (Fig. 6), numa situação em que o limite da sequência coincide com a superficie transgressiva.

Transgressão de oeste para leste foi interpretada há 50 anos por Maack (1946) para o Devoniano do Estado do Paraná. Este cenário paleogeográfico de terras emersas a leste e oceano a oeste é compatível com a diminuição para oeste da porcentagem de caolinita e aumento do teor de boro no mesmo sentido (Rodrigues e Quadros 1976). Os poucos dados de paleocorrentes de fácies deltaicas do Membro Tibagi em Goiás (Fig. 9) e a cunha de fácies interpretada por Andrade e Camarço (1980) também se ajustam a esta interpretação.

\section{EVIDÊNCIAS DE TECTONISMO SINSED1MENTAR}

O mapa de isópacas da Formação Furnas evidencia que a unidade é tabular, com pequenas variações na sua espessura, reflexo de deposição em condições de estabilidade tectônica (Assine 1996).

Geometria diferente é mostrada pelo mapa de isópacas da Formação Ponta Grossa, onde se sobressaem as sub-bacias de Alto Garças e Apucarana (Fig. 1). A configuração apresentada é em grande parte resultado de movimentação tectônica e erosão diferencial durante a geração da discordância eocarbonífera, que separa a Formação Ponta Grossa dos estratos neocarboníferos sobrepostos do Grupo Itararé, fato já destacado por diferentes autores (para citar alguns: Petri e Fulfaro 1967, Assine 1996, Milani 1997).

No Eocarbonífero, falhas do embasamento cristalino foram reativadas e contribuíram para definir os contornos das duas sub-bacias. Uma das mais ativas foi a Falha Lancinha-Cubatão, em cujo bloco alto (sudeste) a Formação Ponta Grossa foi quase totalmente removida por erosão, assentando-se o Grupo Itararé diretamente sobre o embasamento cristalino. Falhas eocarboníferas de direção NW foram verificadas em afloramentos na região de Itapeva por Petri e Fulfaro (1967), sugerindo atividade ao longo do Lineamento de Guapiara.

Algumas evidências apontam, entretanto, para a atuação de tectonismo sinsedimentar ao tempo da deposição da Formação Ponta Grossa. Como já referido anteriormente, dados bioestratigráficos apresentados por Lange (1967) e Daemon et al. (1967) mostram falta de seção correspondente aos intervalos bioestratigráficos D2 e D3 (Emsiano / Eifeliano) nos poços 2-TL-1-MS (Três Lagoas), 2-RP-1-MS (Ribas do Rio Pardo) e 2-PP-1-SP (Paraguaçu Paulista). Tais dados permitiram a Northfleet et al. (1969) interpretar o Arco de Campo Grande e o Alto de Três Lagoas, duas feições estruturais sindeposicionais, possivelmente ligadas, separando as sub-bacias de Alto Garças e Apucarana.

Os novos dados de subsuperfície e a reavaliação de dados de poços antigos, incorporados no mapa de isópacas da figura 1 , reforçam a interpretação de um alto contínuo separando as duas sub-bacias, aqui referido de forma simplificada como Alto de Campo Grande - Três Lagoas. Com sua ativação tectônica no Devoniano, a área entre as duas sub-bacias tornou-se menos subsidente e/ou em soerguimento durante o Emsiano / Eifeliano, não tendo ficado preservado sobre ela 


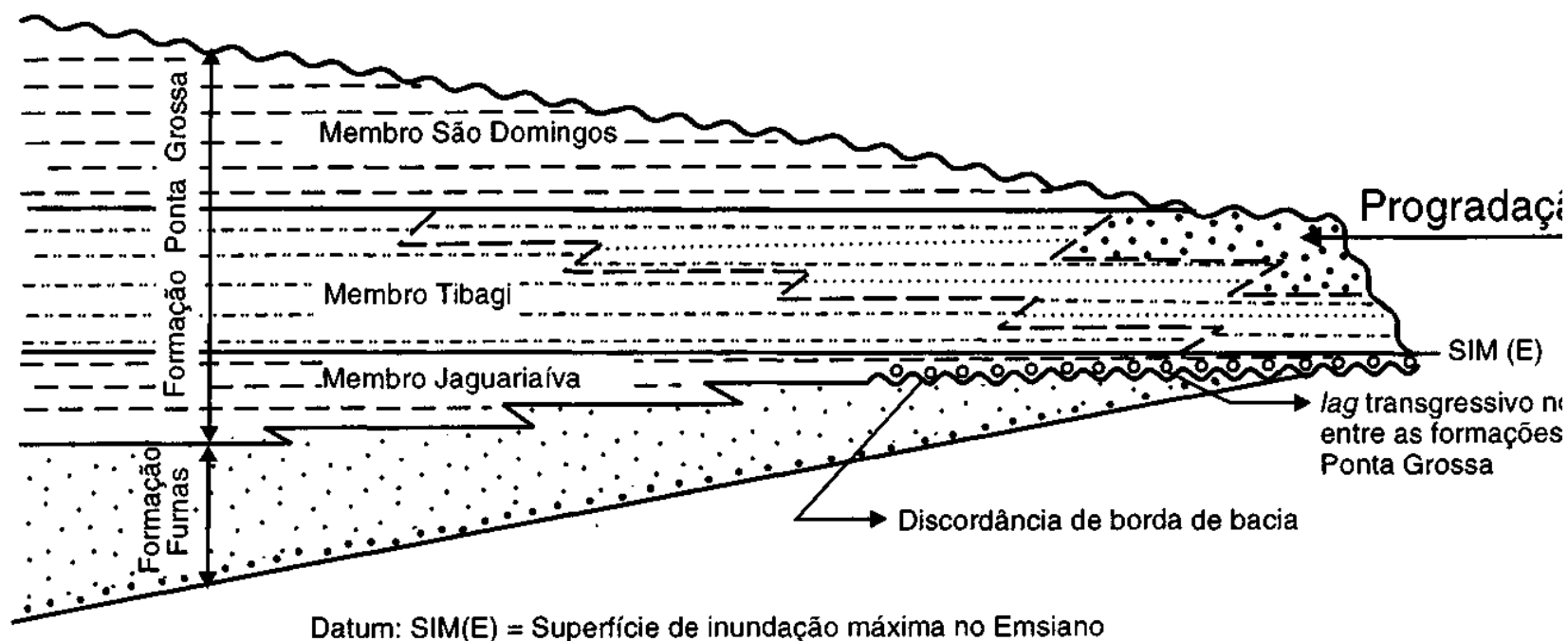

SW

Figura 10 - Seção estratigráfica esquemática mostrando truncamento erosivo da Formação Furnas pela Formação Ponta Grossa no Estado de Goiás, caracterizando discordância de baixo ângulo.

Figura 10 - Schematic stratigraphic section showing low angle unconformity between Furnas and Ponta Grossa formations, as deducedfrom analysis in Southern Goiás State.

registro da porção inferior da Formação Ponta Grossa (Fig. 5). A direção e a natureza do Alto de Campo Grande - Três Lagoas ainda não puderam ser estabelecidas com segurança, mas é sugestiva a interveniência de falhas relacionadas ao Lineamento de Guapiara em sua génese.

Sendo o alto sindeposicional, as duas sub-bacias comportaram-se como dois depocentros principais durante a deposição da Formação Ponta Grossa no Mesodevoniano. Não há dados até o momento que permitam verificar se havia descontinuidade física entre os dois depocentros ou subbacias, ou se, apesar de subsidência diferenciada, havia conexão de suas águas no sentido norte-sul. A insuficiência de dados de subsuperfície não permite concluir também se a geometria da sub-bacia de Alto Garças foi condicionada por falhamentos contemporâneos. O mapa de isópacas (Fig. 1) sugere apenas que falhamentos importantes na história posterior da bacia, como os relacionados ao Lineamento Transbrasiliano, não foram ativos durante a deposição da Formação Ponta Grossa.

Na sub-bacia de Alto Garças há progressiva diminuição da espessura da Formação Furnas para leste e nordeste no sul do Estado de Goiás, onde a Formação Ponta Grossa trunca com pequena angularidade os estratos da Formação Furnas (Fig. 10). A espessura da Formação Furnas é de apenas $10 \mathrm{~m}$ a sul da cidade de Amorinópolis (Fig. 9), sendo o contato com a Formação Ponta Grossa marcado pela presença de lags transgressivos. A discordância entre as formações Furnas e Ponta Grossa, que desaparece em direção às partes mais profundas da bacia (não existe nos poços 2- JA-1-GO e 2-AG-1-MT), caracteriza-se como descontinuidade de borda.

A discordância é considerada produto de movimentação tectônica da borda nordeste da bacia a partir do Emsiano. A existência dos lags no contato evidencia transgressão erosiva, caracterizando limite de sequência deposicional coincidente com superfície transgressiva. A progradação deltaica do Membro Tibagi em Goiás foi assim favorecida pela reativação tectônica das áreas-fonte, que perdurou até o Eifeliano, resultando num padrão nitidamente progradacional com afluxo vindo de nordeste (Fig. 9).

A geometria da sub-bacia de Apucarana apresenta forte controle por falhas NE do embasamento pré-cambriano
(Jacutinga, Guaxupé) e por falhas NW associadas ao Lineamento de Guapiara. Descontinuidades de borda de bacia não foram constatadas na faixa aflorante da Formação Ponta Grossa no Estado do Paraná, que representa o empilhamento de porções distais hoje expostas em consequência do soerguimento mesozóico do Arco de Ponta Grossa. Fácies deltaicas não ocorrem e o Membro Tibagi é constituído por fácies marinhas de plataforma. Estudos de subsuperfície no oeste do Estado de São Paulo (Pontal do Paranapanema) e norte do Paraná permitiram concluir que o afluxo sedimentar provinha de áreas-fonte a leste, corroborando a interpretação de progradações para oeste.

Os poços 2-AN-1-PR (Altônia) e 1-API-1-PR (Alto Piquiri), perfurados no oeste do Estado do Paraná, nas proximidades da divisa com o Paraguai, assim como os poços perfurados no Paraguai (Assunção 1 e 2), apresentam altos valores de razão areia/argila no intervalo correspondente ao Membro Tibagi, sugerindo que o Arco de Assunção possivelmente já constituía elemento geotectônico ativo. Areas a norte (região da Serra da Bodoquena no Brasil) e a sul de Assunção (região do Alto de Caacupu no Paraguai) possivelmente já tinham expressão geomorfológica e funcionavam como áreasfonte. Contudo, o Arco de Assunção ainda não se apresentava plenamente desenvolvido, permitindo conexão da Bacia do Paraná com a Bacia do Chaco, especialmente através do Baixo de São Pedro (Perinotto 1997).

CONCLUSÕES A subdivisão litoestratigráfica tripartite da Formação Ponta Grossa em membros Jaguariaíva, Tibagi e São Domingos, proposta por Lange e Petri (1967), é aplicável em toda a bacia. Sua utilização é recomendável pois evita multiplicidade de denominações, simplificando a comunicação geológica e o entendimento da evolução tectono-sedimentar da Bacia do Paraná no Devoniano.

O Membro Tibagi materializa evento regressivo que se interpôs no contexto geral transgressivo da Formação Ponta Grossa. Os arenitos estão organizados em parasseqüências que apresentam padrão geral de granocrescência e espessamento para o topo, constituindo ciclos limitados por superfícies de inundação marinha. $\mathrm{O}$ padrão de empilhamento é 
repetitivo em toda a bacia caracterizando progradações deltaicas em trato de sistemas de mar alto.

A compartimentação da Formação Ponta Grossa em duas sub-bacias, a existência de altos sindeposicionais onde ocorrem lacunas no registro sedimentar e a ativação das áreas-fonte na borda nordeste, com erosão da Formação Furnas e truncamento pela Formação Ponta Grossa, indicam atuação de tectônica sinsedimentar no Devoniano Médio da Bacia do Paraná.

O Membro Tibagi apresenta características distintas nas faixas de afloramento dos flancos nordeste (Goiás) e sudeste (Paraná). Não constituem seções paleogeograficamente contíguas, estando distantes centenas de quilómetros, mas compõem modelo de trato de sistemas deposicionais de mar alto. No Estado de Goiás, fácies deltaicas com. empilhamento progradante lateralmente transicionam para sistemas marinhos em direção ao depocentro da sub-bacia de Alto Garças. No Estado do Paraná, os arenitos do Membro Tibagi constituem barras de costa-afora construídas por ondas de tempestade, não tendo ficado preservados os depósitos deltaicos contíguos, devido sua remoção por erosão com o levantamento do Arco de Ponta Grossa no Mesozóico.

No Givetiano (Membro São Domingos), o empilhamento passou a ser transgressivo, afogando os sistemas deltaicos que caracterizam o Membro Tibagi. Com a transgressão, o Alto de Campo Grande - Três Lagoas foi recoberto por águas marinhas, permitindo livre comunicação marinha entre as sub-bacias de Apucarana e Alto Garçcas. Após superficie de inundação máxima no Givertiano, a sedimentação prolongouse até o Frasniano com caráter geral regressivo. Erosão no Eocarbonífero foi responsável pela discordância no topo da Formação Ponta Grossa e preservação desigual do Membro São Domingos.

Agradecimentos Os autores externam seus agradecimentos à FAPESP (proc. 1995/0770-0) pelo apoio à pesquisa; a dois relatores da RBG pela revisão do texto e sugestões apresentadas; à Petrobrás pela autorização para publicação de perfis de poços; e ao desenhista António Cezário Porta Jr. pelas ilustrações.

\section{Referências}

Andrade, S.M. e Camarço, P.E.N. 1980. Estratigrafia dos sedimentos devonianos do flanco nordeste da Bacia do Paraná. In: SBG, Congr. Brás. Geol., 31, Camboriú. Anais, 5: 2828-2836.

Assine, M.L. 1995. A natureza do contato entre as formações Furnas e Ponta Grossa. . In: UFRGS, Simp. Cronoestrat. Bacia do Paraná, 2, Porto Alegre. Boi. Resumos Expandidos, 30-31.

Assine, M. L. 1996. Aspectos da Estratigrafia das Sequências Pré-Carboníferas da Bacia do Paraná no Brasil. São Paulo, Instituto de Geociências, Universidade de São Paulo, Tese de Doutoramento, 207p.

Assine, M. L.; Soares, P. C.; Milani, E. J. 1994. Sequências tectono-sedimentares mesopaleozóicas da Bacia do Paraná, Sul do Brasil. Rev. Brás. Geociências, 24(2): 77-89.

Daemon, R. F.; Quadros, L. P.; Silva, L. C. 1967. Devonian palynology and biostratigraphy of the Paraná Basin.. Boi. Paranaense Geociências, 21/22:99-131.

Diniz, M. 1985. Interpretação Ambiental da Formação Ponta Grossa na Parte Central da Bacia do Paraná -um Estudo de Subsuperficie. Instituto de Geociências, Universidade de São Paulo, São Paulo, Dissertação de Mestrado, 148p.

Lange, F. W. 1967. Bioestratigraphic subdivision and correlation of the Devonian in the Paraná Basin. Boi. Paranaense Geociências, 21/22: 63-98.

Lange, F.W. e Petri, S. 1967. The Devonian of the Paraná Basin. Boi. Paranaense Geociências, 21/22: 5-55.

Loboziak, S.; Melo, J.H.S.; Steemans, P.; Barrilar, I.M.R. 1995. Miospores evidence for pre-Emsian and latest Famennian sedimentation in the Devonian of the Paraná basin, south Brazil. An. Acad. Brás. Ci., 67(3): 391-392.

Maack, R. 1946. Geologia e geografia da região de Vila Velha, Estado do Paraná, e considerações sobre a glaciação carbonífera no Brasil. Curitiba, Arquivos do Museu Paranaense, V: 1-305.

Maack, R. 1950-51. Vestígios pré-devonianos de glaciação e a sequência de camadas devonianas no Estado do Paraná. Curitiba, Arquivos de Biologia e Tecnologia (IBPT), V-VI: 197-230.

Melo, J.H.G. 1988. The malvinokaffric realm in the Devonian of Brazil. In: McMillan, N. J. et al. (eds.) Devonian of the World. Can. Soe. Petrol. Geol., 669-703 (Memoir 14)

Milani, E. J. 1997. Evolução Tectono-Estratigráfica da Bacia do Paraná e seu Relacionamento com a Geodinâmica Faneroióica do Gondwana Sul-Ocidental. Porto Alegre, Instituto de Geociências, Universidade Federal do Rio Grande do Sul, Tese de Doutoramento, 2v, 255p.

Northfleet, A. A.; Medeiros, R. A.; Muhlmann, H. 1969. Reavaliação dos dados geológicos da Bacia do Paraná. Boi. Técnico da Petrobrás, 12: 291-346.

Oliveira, E.P. 1927. Geologia e recursos minerais do Estado do Paraná. Brasil, Serviço Geológico e Mineralógico, 172p. (Monografia 6)

Perinotto, J. A. J. 1997. Análise Estratigráfica dos Grupos Rio Ivaí(OS), Paraná (D) e Aquidauana (CP) -Bacia Sedimentar do Paraná - no Centro-Oeste Brasileiro. Rio Claro, Instituto de Geociências e Ciências Exatas, Universidade Estadual Paulista, Tese de Livre-Docência, $147 \mathrm{p}$.

Petri, S. 1948. Contribuição ao estudo do Devoniano paranaense. Rio de Janeiro, DNPM/DGM, 125p. (Boletim 129)

Petri, S.; Fulfaro, V. J. 1967. Considerações geológicas sobre a região de Itapeva, São Paulo. Boi. Soe. Brás. Geologia, 16: 25-40.

Popp, J.H.; Barcellos-Popp, M. 1986. Análise estratigráfica da sequência devoniana da Bacia do Paraná (Brasil). Rev. Brás. Geociências, 16:187-194.

Ramos, A. N. 1970. Aspectos páleo-estruturais da Bacia do Paraná e sua influência na sedimentação. Boi. Técn. Petrobrás, 13: 85-93.

Rodrigues, R.; Quadros, L.P. 1976. Mineralogia das arguas e teor de boro das formações paleozóicas da Bacia do Paraná. In: SBG, Congr. Brás. Geol.,29, Ouro Preto. Anais, 2: 351 -379.

Manuscrito A-948

Recebido em 25 de novembro de 1997 Revisão dos autores em 08 de abril de 1998 Revisão aceita em 12 de abril de 1998 